\title{
Dominik Rumpf
}

\section{Zinsbereinigung bei der Dualen Einkommensteuer}

Die Unternehmensteuerreform 2008 und der Vorschlag einer »Zinsbereinigung des Grundkapitals«

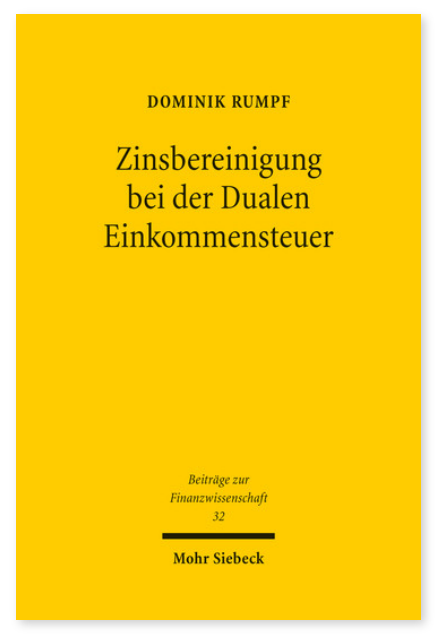

2013. XXIV, 238 Seiten. BtrFin 32

ISBN 978-3-16-152881-1

DOI 10.1628/978-3-16-152881-1

eBook PDF $74,00 €$

ISBN 978-3-16-152869-9

fadengeheftete Broschur 74,00€
Vor dem Hintergrund des internationalen Steuerwettbewerbs hat sich die Unternehmens- und Kapitalertragsbesteuerung in den letzten Jahren schrittweise von ihrem ursprünglichen Leitbild entfernt. Mit der letzten umfassenden Reform der Jahre 2008/2009 wurden einzelne Elemente einer Dualen Einkommensteuer umgesetzt. Dominik Rumpf analysiert die komplexen Wirkungen dieses Mischsystems. Zentrale Nachteile sind, dass zum einen die Eigenkapitalfinanzierung gegenüber der Fremdfinanzierung benachteiligt wird, und zum anderen umfangreiche Möglichkeiten zur Steuergestaltung bestehen. Mit der »Zinsbereinigung des Grundkapitals« wird ein Reformvorschlag entwickelt, der den eingeschlagenen Weg zur Dualen Einkommensteuer vollenden würde. Gegenüber anderen Optionen zeichnet er sich durch verhältnismäßig geringe Steuermindereinnahmen und vorteilhafte Wirkungen im internationalen Steuerwettbewerb aus.

Dominik Rumpf Geboren 1983; 2002-06 Studium der Volkswirtschaftslehre in Tübingen; 2006-10 wissenschaftlicher Mitarbeiter am Lehrstuhl für Betriebswirtschaftliche Steuerlehre von Prof. Dr. Dirk Kiesewetter; seit April 2010 Referent beim Sachverständigenrat zur Begutachtung der gesamtwirtschaftlichen Entwicklung in Wiesbaden; 2013 Promotion an der Universität Würzburg
Jetzt bestellen:

https://mohrsiebeck.com/buch/zinsbereinigung-bei-der-dualen-einkommensteuer-9783161528811?no_cache=1 order@mohrsiebeck.com

Telefon: +49 (0)7071-923-17

Telefax: +49 (0)7071-51104 